\title{
LA PROBLEMÁTICA SILVA ESPAÑOLA
}

Para la poesía vernácula, el Renacimiento significaba la invención de un nuevo sistema clásico de géneros; esto se ve claramente en la poesía de Boscán y Garcilaso ${ }^{1}$. Como explica Fowler², reconocer el código genérico de un poema es un requisito para saber leerlo. Pero no siempre son muy claras las fronteras entre los distintos géneros; son inestables, ya que influyen cruces y accidentes históricos, y un poema puede participar en más de un género. Cada género histórico tiene su propio repertorio de características, del cual están más o menos conscientes los poetas y sus lectores: cierto tipo de discurso, secuencia de subdivisiones, estructura métrica, extensión, temática, tono ético, etcétera. Los géneros poéticos son como pequeñas instituciones sociolingüísticas, altamente convencionales, que se van modificando colectivamente. En la tradición renacentista del Ars poetica horaciana, las formas métricas y estróficas tendían a ser definidoras; es evidente esto en las Anotaciones de Herrera. Así, por ejemplo, las formas petrarquistas más típicas, la canción y el soneto, se redefinen clásicamente como oda y epigrama. El terceto italiano, o terza rima, llegó a considerarse como equivalente del dístico elegíaco, y los versos sueltos como hexámetros dactílicos; así es que la elegía ovidiana se imitaba vernáculamente en tercetos, y la primera epístola horaciana de la poesía española se escribió en versos sueltos ${ }^{3}$. No sería difícil inventariar de esta manera los géneros clásicos de la poesía española del siglo XVI, incluyendo las sátiras, las églo-

${ }^{1}$ Elias Rivers, "El problema de los géneros neoclásicos y la poesía de Garcilaso", Academia Literaria Renacentista, Salamanca, 1986, núm. 4, 49-60.

${ }^{2}$ Alastair Fowler, Kinds of literature: An introduction to the theory of genres and modes, Harvard University Press, Cambridge, MA, 1982.

${ }^{3}$ E. Rivers, "The horatian epistle and its introduction into Spanish literature', $H R, 22$ (1954), 175-194. 
gas, las fábulas, las odas pindáricas y horaciaras; cada género podría definirse sincrónicamente por su métrica y su discurso, y diacrónicamente por sus modelos antiguos y su desarrollo histórico. Y estos géneros tendían a definirse también por oposición mutua dentro de un sistema clásico; pero algunos géneros eran más estables que otros, y algunas partes del sistema fluctuaban notablemente. Tanto los poetas como los lectores conocían las convenciones genéricas que hacían inteligibles los poemas individuales.

Hay buenos estudios recientes sobre los géneros clásicos en España pero sigue siendo ejemplar para el siglo xvi el de Claudio Guillén sobre "Sátira y poética en Garcilaso"'. A Garcilaso no se le suele considerar como poeta satírico, pero, según demuestra Guillén, al final de su Epistola y al principio de su Elegía II. el discurso ético se hace típicamente satírico, y el poeta se lo señala explícitamente al lector en los versos 22-24 de la elegía:

Mas ¿dónde me llevó la pluma mía?, que a sátira me voy mi paso a paso, y aquesta que os escribo es elegía.

Varios géneros diferentes - la sátira, la elegía, la epístola, la oda horaciana- pertenecían a un solo sistema clásico de oposiciones y polaridades que justamente en esa época se iba estableciendo en la poesía vernácula europea. Garcilaso sabía que uno de sus grandes modelos, Sannazaro, había escogido los tercetos para la elegía, y que Bernardo Tasso experimentaba con várias estrofas breves para la oda horaciana: de ahí la lira garcilasiana. Las Heroiáas de Ovidio, escritas en dísticos elegiacos, llevaban hacia los tercetos a la epístola horaciana, escrita en hexámetros. En la Elegía II de Garcilaso se reúnen elegía, epístola y sátira, pero la oposición primaria es la binaria horaciana entre sátira y epístola: el estilo cómicamente vulgar de la crítica social se diferenciaba claramente del estilo moderado de la amistosa filosofía moral. Los poetas renacentistas y sus lectores, en los años 1530, querían establecer una diferencia entre estos dos contragéneros, que eran dos códigos distintos para la escritura y lectura de dos conjuntos

4 Véanse, por ejemplo, José Jesús de Bustos Tovar, "La elegía como forma del discurso poético", en Teoría del discurso poético, Toulouse, 1986, pp. 9-20; Lía Schwartz Lerner, "Formas de la poesía satírica en el siglo XVII: sobre las convenciones del género", Edad de Oro, 6 (1987), 215-234.

${ }^{5}$ HJC, pp. 209-233. 
diferentes de poemas. Éste, en resumen, es el análisis que hace Guillén de la situación genérica en ese momento histórico.

Unos sesenta y cinco años más tarde, a principios del siglo XVII, se desarrollaban otros esquemas métricos y géneros poétieos españoles. El más notable de éstos era la silva. Karl Vossler fue el primer hispanista moderno que asociara la silva como género con su principal modelo clásico, la silva latina de Estacio ( $\mathrm{Pu}$ blius Papinius Statius), defendida e imitada por el humanista italiano Poliziano. En su gran libro La poesía de la soledad en España Vossler escribió a propósito de la poesía pastoril un breve excursus sobre la silva, señalando antecedentes métricos en la poesía italiana de Folengo. Podríamos añadir los nombres de Tansillo y de Grazzini, inventor de la burlesca madrigalessa, pero a mí me parece más importante la poesía de Bernardo Tasso. Como ya hemos visto en el caso de la lira, los experimentos de Bernardo Tasso se conocían y se imitaban en España. En sus Rime. . divise in cinque libri nuovamente stampate? encontramos una "Selva nella morte di Luigi Gonzaga"' escrita en una serie de más de 200 endecasílabos, con rimas irregulares y poco frecuentes, además de un libro de salmos y un libro de odas e himnos, todos escritos en estrofas breves de canzone italiana. En su introducción general al tomo, Tasso subraya "la novità de miei versi" al trasladarse desde los géneros italianos (sonetos y canciones) hacia los géneros clásicos ("Hinni, Ode, Egloghe, \& Selve"), "dando a divedere alle genti, la poesia degli antichi, colta dalle mani moderne, esser atta a rinovellarsi fra noi di fiori e di frutti d'altrettanta bellezza di quanta Roma o Athene gli producesse giamai. Ne sia chi dica la lingua Thoscana non esser degna dell' honore. . .'. Dice además que nadie debe criticar sus himnos y odas por falta de rimas, "le cui vo$c i$ in picciola stanza rinchiuse, subitamente a guisa d'Echo, una \& due volte vanno iterando il suono proposto. . ." . El "verso puro esametro" ha sido para él un desafío más grande, y en este caso ha reducido a un mínimo las rimas, separándolas todo lo posible. "Ma posto che vitio fosse ne miei versi il celar l'armonia della rima, veramente non è da loro il difetto, nei quali senza piu indugio, di quarto in quarto cortesemente parla \& risponde la rima...". Ésta parece ser la norma en su "selva", pero otros poemas tienen rimas más distantes, y su Favola di Leandro es un poema de más de 700 versos sueltos, sin rima alguna.

\footnotetext{
${ }^{6}$ Losada, Buenos Aires, 1946.

${ }^{7}$ Giolito de' Ferrari, Vinegia, 1560.
} 
Vossler sabía que en la Universidad de Salamanca Francisco Sánchez de las Brozas (Sanctius Brocensis) había publicado para sus estudiantes, en 1554 y 1596, dos ediciones comentadas de las Silva de Poliziano ${ }^{8}$. En 1607 Jáuregui publicó su famosa traducción del Aminta de Torquato Tasso, usando generalmente versos sueltos, con algún heptasílabo entreverado, y para los coros usando rimas en estrofas de canción, romancillo heptasilábico, octavas y silva. Este fue probablemente el texto más influyente en la tradición que establece Vossler de una silva pastoril española, incluyendo poemas como el de Pedro Espinosa ("Selvas donde en tapetes de esmeralda", publicado en sus Flores de poetas ilustres de España de $1605^{9}$ ), el "Acaecimiento amoroso" de Jáuregui (publicado en sus Rimas de $1618^{10}$ ) y, por supuesto, la Soledad I de Góngora, que circulaba en manuscrito desde 1613. Vossler añade a esta lista varios poemas de Lope de Vega, que van desde algunos publicados en Los pastores de Belén (1611) hasta su "Siglo de oro (silva moral)" de 1635.

Lo que se le escapó totalmente a Vossler fue que otro gran poeta barroco de España, Francisco de Quevedo, había escrito silvas muy importantes, con una clara conciencia de la tradición estaciana. Este hecho ha sido aclarado por el erudito crítico literario don Eugenio Asensio, quien en 1983 publicó un brillante ensayo titulado "Un Quevedo incógnito: las silvas"'11. Estudiando las agrupaciones de poemas en manuscritos e índices de la poesía de Quevedo, Asensio pudo demostrar que el poeta había escrito 36 silvas humanísticas entre los primeros años del siglo y el final de su vida. Cinco de ellas se incluyeron en la segunda parte de las Flores de poetas ilustres de España, recogidas (pero no publicadas) en 1611. Y una de estas silvas, la titulada "Al sueño",, se basa directamente en una de las Silva de Estacio, la número 4 del Libro V, titulada "Somnus", la más breve y quizá la más popular de todas. En 1986 dos eruditos de Estados Unidos, James Crosby y Lía Schwartz Lerner, publicaron un análisis exhaustivo del poema latino y del complejo proceso de imitación y revisión al cual

${ }^{8}$ Francisco Sánchez de las Brozas (ed.), Angeli Politiani Silva. . cum scholiis Francisci Sanctii Brocensis. .., Petrus Lassus, Salmantica, 1596.

${ }^{9}$ Pedro Espinosa, Poesías completas, ed. Francisco López Estrada, EspasaCalpe, Madrid, 1975.

${ }^{10}$ Cf. Juan de Jáuregui, Obras, ed. Inmaculada Ferrer de Alba, EspasaCalpe, Madrid, 1973, t. 1.

${ }^{11}$ Eugenio Asensio, "Un Quevedo incógnito: las silvas", Edad de Oro, 2 (1983), 13-48. 
lo sometió Quevedo' ${ }^{12}$. Según este análisis, el texto de 1611, aunque truncado, representa la primera versión; otro manuscrito, con retoques autógrafos, refleja una segunda etapa, que pertenece a los años 1613-1616; la versión final que se publicó póstumamente en 1670 refleja esta segunda etapa de revisión, y también otra posterior, la cual pertenece probablemente al año 1624. Así es que ahora, con el estudio de Asensio, que coloca en un amplio contexto histórico y teórico las silvas de Quevedo, y con el análisis enfocado en la relación entre el texto antiguo de 19 versos y el texto español de 93 versos, tenemos una base muy firme para el estudio del género barroco por excelencia de la poesía española.

Lo primero que hay que reconocer es que la silva española no se define nunca tan claramente, ni por su origen ni por su desarrollo, como por ejemplo la oda horaciana. Las odas de Horacio constituían ya una clase coherente de poesía, aunque con cierta variedad estrófica; su discurso se basaba en una fusión personal de estoicismo y de epicureanismo morales actualizada en términos de una modesta vida cotidiana y dirigida a un amigo en cierta ocasión particular. Las odas de Horacio fueron imitadas por poetas neolatinos e italianos, especialmente por Bernardo Tasso, cuyas breves estrofas encabalgadas fueron el modelo de Garcilaso, quien escribió, además de tres odas en latín, su oda en español titulada "Ode ad florem Gnidi", la cual tuvo una gran influencia genérica en España. Luego un grupo de poetas académieos en Salamanca, dirigido por Fray Luis de León, empezó hacia 1570 a traducir al español odas selectas de Horacio; cuatro de las traducciones de Fray Luis fueron publicadas en 1574 por El Brocense en sus anotaciones a la poesía de Garcilaso ${ }^{13}$. De ahí en adelante hubo una tradición continua de traducciones e imitaciones de las odas de Horacio: Fray Luis mismo, Francisco de la Torre, Medrano, Herrera, Espinel, Villegas y otros muchos. La primera parte (1605) de las Flores de poetas ilustres contiene numerosas odas de Horacio traducidas al español. Cada poeta volvía constantemente a los familiares modelos horacianos, que daban siempre una definición muy clara al género. Así fue que sin mayores problemas pudo escribir Menéndez y Pelayo su gran monografía sobre Horacio en España. Muy diferente es el caso de la silva española.

12 James O. Crosby y Lía Schwartz Lerner, "La silva "El sueño» de Quevedo: génesis y revisiones", BHS, 63 (1986), 111-126.

${ }^{13}$ E. RIVERs, "Fray Luis de León: traducción e imitación", Edad de Oro, 4 (1985), 107-115. 
Es complicada la cuestión de la influencia en España de las Silva de Estacio, que seguramente no se leían tanto en las clases de latín como las odas de Horacio. Y la silva estaciana es de por sí más difícil de definir como género poético. Escritas con pocas excepciones en hexámetros dactílicos, las Silva eran poemas ocasionales. El título genérico, influido por su doblete griego hyle, significaba no sólo selvas sino también una abundancia de materia natural. En el prefacio de su Libro I Estacio subraya la espontaneidad y rapidez de su composición: "hos libellos, qui mihi subito calore et quadam festinandi voluptate íluxerunt' '. Quintiliano define en términos parecidos la silva latina; así vemos que había de dar una impresión de improvisación. Y sin embargo cada silva de Estacio pertenecía a una categoría retórica bien definida: hay epicedia, ekphrases, epithalamia, propemptica, genethliaca, soteria (canciones fúnebres, descripciones, canciones de boda, de despedida, de cumpleaños, de salud recuperada). . . Cada categoría en cierto sentido constituye un género, o una especie, diferente. Quizá, como dice Asensio, la silva más típica es la descriptiva: Estacio describió una estatua del Emperador, la villa de un amigo, sus baños, su árbol, un templo... Pero 'Somnus', nuestro punto de contacto más directo, no es una silva típica: con la brevedad de un soneto, es la dolorosa petición de un insomne que se dirige al dios del sueño. (Hugo Friedrich escogió este poema como ejemplo típico del manierismo literario $)^{14}$.

La edición que hizo El Brocense de las silvas de Poliziano llamaría la atención en España sobre el género, pero estas silvas no eran base de imitación ni experimentación. Aunque escritas en hexámetros, las silvas de Poliziano se parecían poco a las de Estacio: son mucho más largas (600-800 versos) y, como dice Asensio, son praelectiones, o conferencias académicas, sobre poesía clásica. Por eso se usaban en Salamanca como texto universitario. Lo único interesante de esta edición, me parece, es el propio comentario de El Brocense sobre la palabra "silva":

Silva, Nemus, \& Saltus diferunt. In silva sunt arbores siue cæduæ siue incasduæ. . .Saltus est ubi silua: \& pastiones sunt. Nemus etiam a pastione, vel pascendo dictus Gracis, sed est magis locus voluptatis causa paratus, siue arte, siue natura constet. Siluae rursus per translationem dicuntur illa, quæ congeruntur \& comparan-

${ }^{14}$ Hugo Friedrich, "Über die Silvae des Statius (insbesondere V, 4, Somnus) und die Frage des literarischen Manierismus", Wort und Text: Festschrift für Fritz Schalk, Frankfurt, 1963, 34-56. 
tur ad componendum librum, vel orationem. Cic.3.Orat. Primum silua rerum, ac sententiarum comparanda est. Sed crediderim potius Politianum Siluarum inscriptione delectatum, eo quod in siluis scripserit, \& in secreto nemore. Nam in Fesulano nemore, ut in fine prima: silua: fatetur, sedem habebat.

El ambiente silvano del escritor mismo es una idea original, que no deja de apoyar la asociación que hace Vossler entre la silva y la poesía de la soledad.

La imitación que hizo Quevedo del "Somnus" parece ser el contacto más directo entre el texto de las silvas de Estacio y la rica tradición de la silva española durante el siglo xvII; desde luego no hubo ninguna escuela de traductores e imitadores, como en el caso de Horacio. Las silvas de Quevedo tienen por eso una importancia fundamental; como dice Asensio, al morir este poeta en 1645, dejó un grupo sustancial de 36 silvas, "un equívoco corpus en que alternaban silvas estacianas y silvas métricas". Por "silva métrica" Asensio quiere decir un nuevo género prosódico que ya en 1624 ofrecía "una fácil transición hacia una poesía ya lírico-descriptiva, ya reflexiva, ya narrativa, ya didáctica...',15

También merece atención otro corpus de silvas españolas, escritas ya antes de la explosión genérica que significó en 1613 la Soledad I de Góngora: son las once silvas de Francisco de Rioja ${ }^{16}$. Su editora más reciente, Begoña López Bueno, teniendo en cuenta los estudios de Vossler y de Asensio, les dedica unas pocas páginas. Pasa por alto la Silva I de Rioja, que es quizá la más interesante y seguramente la más sofisticada y enigmática, basada en un texto griego, en prosa, del siglo iv. En esta silva un pintor se dirige a Apolo protestando que no puede representar en una tabla de laurel al dios solar. El pintor ha podido representar sin problema a otras figuras mitológicas: a Aurora, a una ninfa, a Marte. Ahora encuentra una explicación mitológica de su fracaso con el sol: la castidad de Dafne, implicada en la tabla de laurel, opone resistencia todavía a la violación de Apolo. Esta silva, digna de Estacio mismo, parece ser una alegoría platónica del fracaso del arte material, incapaz de representar los conceptos ideales que existen en la mente del artista. Las diez silvas restantes de Rioja se dividen, según Begoña López, en dos grupos claramente dife-

15 Asensio, art. cit.

${ }^{16}$ Francisco de Rioja, Poesia, ed. Begoña López Bueno, Cátedra, Madrid, 1984. 
rentes. Las Silvas II, III, IV y V se acercan moralmente a ciertas odas de Horacio: las dos primeras yuxtaponen los temas de la riqueza y la pobreza al concepto de la aurea mediocritas, y las otras dos proponen para amigos el ejemplo estoico de la constancia del poeta ante adversidades. El segundo grupo, de seis silvas, se basa por contraste en el tenia del carpe diem: la llegada de la primavera, las famosas descripciones de varias flores (rosas diferentes, la arrebolera, el clavel, el jazmín), la breve duración de su hermosura. Son silvas ecfrásticas, como muchas de las de Estacio. La marca común de todas las silvas de Rioja es el apóstrofe: la voz poética se dirige a un amigo humano, al sol, a una flor, a una abstracción. Esta prosopopeya permite, como en las silvas de Estacio, un juego de la primera persona lírica que constituye lo que ha llamado Paul Julian Smith "la retórica de la presencia" en la poesía del Siglo de Oro español ${ }^{17}$. Otra silva de tipo riojano parece ser la única atribuida a Juan de Arguijo, la que éste dirige "A la vihuela".

En la tradición menos estaciana, más pastoril, de Espinosa y Jáuregui, estudiada brevemente por Vossler, Espinosa tiene no sólo su "Llanto", que es silva métrica con pocas rimas, titulada "Canción a manera de boscarecha"'18, un lamento amoroso parecido al de Salicio en la Égloga I de Garcilaso: también escribió en silva métrica parecida su "Epístola al licenciado Antonio Moreno recordando los tiempos felices de sus amores"'19, por no hablar de varios salmos, que desde Montemayor solían escribirse en silva métrica. Y entre la poesía panegírica que dedica al duque de Medina Sidonia, encontramos una "Boscarecha en alabanza del gran duque"'20, que empieza con una octava real y sigue en silva métrica, con algún verso suelto: parece que Espinosa no usaba la palabra silva, sino "boscarecha", para significar sencillamente versificación irregular, con quizá alguna alusión a la silva estaciana en el caso del panegírico. Pero Jáuregui, en sus Rimas tiene dos poemas a los que él da el título de silva: un poema académico dirigido "A un amigo docto y mal contento de sus obras" 21, además del "Acaecimiento amoroso" '22 mencionado por

17 Paul J. Smith, "The rhetoric of presence in poets and critics of Golden Age lyric: Garcilaso, Herrera, Góngora”, MLN, 100 (1985), 223-246.

${ }_{18}$ EsPinOSA, op. cit., núm. 9.

19 Ibid., núm. 10.

${ }^{20} \mathrm{Ibid}$, núm. 63.

${ }^{21}$ JÁUREGUI, op. cit., núm. 30.

22 Ibid., núm. 33. 
Vossler, silva narrativa francamente erótica, en la tradición del Aminta. Las muchas silvas de Lope de Vega reflejarán esta tradición abierta, sin claro sentido genérico, así como las silvas de Jacinto Polo de Medina ${ }^{23}$. Éstas presentan también un corpus heterogéneo, que incluye un epitalamio, una silva moral, y los Ocios de la soledad, combidando a don Luis Marin de Valdés a gozar la hermosura de la aldea (1633). Más típica de Polo es la silva cómica, que encontramos no sólo en una fábula burlesca suya (la de Apolo y Dafne, 1634) sino en una docena de obras satíricas, como por ejemplo su "Silva a una vieja que dijo tenía dentera de comer limón", que tienen antecedentes en las madrigalesse de Grazzini. Ya es difícil ver en estas silvas cuáles son las fronteras genéricas.

Para muchos poetas y lectores del Siglo de Oro, sin embargo, la silva significaba sobre todo la nueva poesía de Góngora, sus Soledades; muy pronto después de su aparición en 1613 se hace esta identificación, en la Plaza universal de todas las ciencias y artes (1615) de Cristóbal Suárez de Figueroa:

Algunos siguen de poco a esta parte un nuevo género de composición (al modo de Estacio en las silvas) fundado en escurecer los concetos con interposiciones de palabras, y ablativos absolutos, sin artículos, aunque cuidadoso en la elegancia de frases y elocuciones. Grandes son las contiendas que causó esta novedad entre los poetas de España, contradiciéndola por una parte muchos, como contraria a la claridad elegante, y por otra siguiéndola algunos, como exquisita y adornada de poéticos resplandores ${ }^{24}$.

Si, como hemos visto, Quevedo con su imitación directa de Estacio, hecha antes de 1611, se podía considerar como uno de los fundadores de la silva española, podemos imaginarnos su disgusto al ver que las Soledades del canónigo cordobés se imponían ya como el nuevo modelo genérico.

¿Cuáles son las características genéricas de la silva gongorina? Tenemos el ejemplar análisis de Nadine Ly, publicado en $1985^{25}$, que toma en cuenta el entonces recién salido ensayo de Eugenio Asensio. Aplicando a las Soledades conceptos derivados de Genette, la hispanista francesa considera detalladamente su forma de discurso (la silva métrica), su modo de enunciación (epos)

${ }^{23}$ Jacinto Polo de Medina, Obras completas, ed. Ángel Valbuena Prat, Murcia, 1948.

24 Madrid, 1615. f. 358

25 "Las Soledades: «Esta poesía inútil. ...", Criticón, 1985, núm. 30, 7-42. 
y su compleja estructura temática. Después de señalar su homogeneidad métrica (la proporción aproximada de $75 \%$ de endecasílabos frente a $25 \%$ de heptasílabos establece su grado cero), Ly llega a la conclusión de que el género de las Soledades no es en efecto la silva sino un género nuevo que se había de llamar soledad. "La soledad-texto inaugura un 'género' poético nuevo, que se deriva de la silva, claro está, pero que, al constituir una innovación, permite la invención de programas métricos, formales y temáticos inéditos . . "26. En cuanto a su modo de enunciación, Ly separa la Dedicatoria de la Soledad I y de la Soledad II. Es evidente la presencia del poeta en la primera sección, dirigida al duque. El peregrino sólo dice tres versos (62-64) en la Soledad I, pero en la segunda enuncia una larga invocación (vv. 123-171) y mantiene un diálogo con el isleño (vv. 363-387 y 388-511), con alternancia de tuteo y voseo. El canto amebeo es también una especie de diálogo. Más importante para la estructura del poema me parece que es el modo narrativo del yo poético, personaje formalmente ausente durante los primeros 93 versos de la Soledad I y luego enunciador del "Oh bienaventurado" y del apóstrofe al pavo (vv. 309-314); también en la Soledad II el narrador se actualiza cuatro veces invocando aves. Y todavía más importante es el yo escritor, que se actualiza tres veces con el verbo "dudo", una vez con "ni creo", y una vez con "digo"; se dirige así al destinatario (duque-lector), incluyéndose con él y con el peregrino en el plural de la primera persona ("nuestro peregrino"). Esta trinidad central se encuentra en la estación de amor, en un mundo erótico que nos lleva a bodas y desposorios, a cacerías y eventualmente a la muerte. En su conclusión Ly afirma la rareza del género nuevo creado por Góngora, su modernidad radical.

Si con sus apóstrofes el discurso de la silva estaciana (quevedesca, riojana) se basaba en la retórica de la presencia del yo lírico, la nueva silva o soledad gongorina cultiva una retórica de la ausencia: en las Soledades, como acabamos de ver, apenas hay deícticos de primera persona relacionados con el narrador o con el protagonista, ese joven peregrino fantasmal ${ }^{27}$. Pero, entre sus numerosos epígonos, Góngora encuentra muy pocos capaces de tal austeridad discursiva. Uno de los más próximos es Pedro Soto de Rojas en su Paraíso cerrado para muchos, jardines abiertos para pocos.

${ }^{26}$ Ibid., pp. 19-21.

27 E. Rivers, "Problems of genre in Golden Age poetry", MLN, 102 (1987), 206-219. 
Los fragmentos de Adonis, del cual dice con gran perspicacia su editora Aurora Egido: "Pero hay una ausencia, la del hombre, que señala su oposición a otros poemas descriptivos. Nadie acompaña al poeta en su peregrinaje, ni siquiera el lector es requerido..." 28 . En efecto, entre la invocación de Clío al principio y la despedida de Euterpe al final (la cual llega "de apóstrofe vestida,/ color bien atendida"), el poeta describe objetivamente los jardines, sin presencia ajena. Pero su propio yo está siempre presente, implícito en los frecuentes deícticos ("aquí", "esto", etcétera). Quizá más radicalmente gongorina es la silva de Agustín de Salazar y Torres titulada "Soledad a imitación de las de don Luis de Góngora" ${ }^{29}$, descripción muy objetiva de la llegada del día.

Terminemos este panorama provisional de la silva española con el gran poema de la mexicana Sor Juana Inés de la Cruz. Su Sueño no es, por supuesto, otra Soledad, pero su estructura discursiva lo identifica genéricamente con la silva o soledad gongorina. Para comparar rigurosamente los dos poemas nos haría falta otro análisis tan exigente como el de Nadine Ly. La silva métrica es parecida, pero su función sintáctica es muy diferente, pues los periodos de Sor Juana son a veces mucho más largos que los de Góngora; es un mundo más racionalmente articulado. No hay dedicatoria ni diálogo; la relativa escasez de personajes humanos es evidente. El Alma es el personaje del Sueño que corresponde plenamente al peregrino de Góngora, mirón erótico de las Soledades que se convierte en la observadora y teórica científica de Sor Juana. Tiene razón Rosa Perelmuter Pérez al afirmar, después de un minucioso examen de los deícticos, que "se trata de una narradora que, aunque escurridiza, deja plena constancia de su existencia - y de su labor ordenadora- a lo largo del poema" "30. Hemos visto que Góngora en sus Soledades es todavía más escurridizo, pero sabemos que él también ordenaba con cuidado su poema, y Ly ha señalado los verbos que indican la presencia del yo escritor. Sin embargo, la retórica de la ausencia es una de las marcas más distintivas de la silva gongorina, de la nueva poesía barroca, en la que el lenguaje mismo es el protagonista. A Quevedo le parecía esto inmoral. Pero, si hubiera podido leer el Sueño y captar su gran seriedad intelectual, quizá se habría dado cuenta de que

${ }^{28}$ Cátedra, Madrid, 1981, p. 43.

${ }^{29}$ En Cyithara de Apolo: Varias poesías divinas y humanas, Francisco Sanz, Madrid; 1981, pp. 34-38.

${ }^{30}$ Rosa Perelmuter Pérez, "La situación enunciativa del «Primero sueño»", RCEH, 11 (1985), p. 190. 
la moralidad no depende del famoso desgarrón afectivo, de la retórica de la presencia, de la cual él era tan maestro como lo iba a ser Unamuno.

ELIAS L. Rivers 